\title{
Uncovered interest parity tests and exchange rate expectations
}

Citation for published version (APA):

Marey, P. S. (2004). Uncovered interest parity tests and exchange rate expectations. METEOR, Maastricht University School of Business and Economics. METEOR Research Memorandum No. 012 https://doi.org/10.26481/umamet.2004012

Document status and date:

Published: 01/01/2004

DOI:

10.26481/umamet.2004012

Document Version:

Publisher's PDF, also known as Version of record

\section{Please check the document version of this publication:}

- A submitted manuscript is the version of the article upon submission and before peer-review. There can be important differences between the submitted version and the official published version of record.

People interested in the research are advised to contact the author for the final version of the publication, or visit the DOI to the publisher's website.

- The final author version and the galley proof are versions of the publication after peer review.

- The final published version features the final layout of the paper including the volume, issue and page numbers.

Link to publication

\footnotetext{
General rights rights.

- You may freely distribute the URL identifying the publication in the public portal. please follow below link for the End User Agreement:

www.umlib.nl/taverne-license

Take down policy

If you believe that this document breaches copyright please contact us at:

repository@maastrichtuniversity.nl

providing details and we will investigate your claim.
}

Copyright and moral rights for the publications made accessible in the public portal are retained by the authors and/or other copyright owners and it is a condition of accessing publications that users recognise and abide by the legal requirements associated with these

- Users may download and print one copy of any publication from the public portal for the purpose of private study or research.

- You may not further distribute the material or use it for any profit-making activity or commercial gain

If the publication is distributed under the terms of Article $25 \mathrm{fa}$ of the Dutch Copyright Act, indicated by the "Taverne" license above, 


\title{
Uncovered interest parity tests and exchange rate expectations
}

\author{
Philip S. Marey
}

ROA, Maastricht University

P.O. Box 371, 6200 AJ Maastricht, The Netherlands

p.marey@roa.unimaas.nl

\begin{abstract}
Empirical studies reject uncovered interest parity. Experimental and survey data studies reject rational expectations and find evidence of adaptive, regressive, bandwagon and distributed lag expectations. In this paper we investigate how these two findings are related. We show that uncovered interest parity test coefficients can be expressed as functions of the parameters of the expectations mechanisms. Negative values for uncovered interest parity test coefficients are explained by adaptive expectations with a high speed of learning and distributed lag expectations, while positive values are caused by adaptive expectations with a low speed of learning, regressive expectations and bandwagon expectations.
\end{abstract}

JEL classification: F31

Keywords: uncovered interest parity, forward premium puzzle, exchange rate expectations, time-varying risk premium, market microstructure.

March 9, 2004

I would like to thank Lex Borghans, Menzie Chinn, Clemens Kool, Guy Meredith, Carol Osler, Tom van Veen, Casper de Vries and participants at the 2002 Research Day of the Netherlands Network of Economics at De Nederlandsche Bank and seminars at Maastricht University and Brandeis University for useful comments and suggestions. 


\section{Introduction}

Uncovered interest parity (UIP) or forward rate unbiasedness are usually rejected in empirical studies. At the same time, experimental and survey evidence on exchange rate expectations often rejects rational expectations (and static expectations) and supports extrapolative, adaptive and regressive expectations. In this paper we show how these two stylized facts of foreign exchange are related. We show that there is a relationship between the variables and parameters of the prevailing expectations mechanism and the sign and size of the UIP-testcoefficient.

A persisting stylized fact of foreign exchange is the rejection of uncovered interest parity in empirical data, also known as the forward premium puzzle. Empirical tests of uncovered interest parity or forward rate unbiasedness ${ }^{1}$ are based on the following regression equation:

$\Delta s_{t}=\rho+\beta\left(I_{t-1}-I_{t-1}^{*}\right)+\varepsilon_{t}$

where $\Delta \mathrm{s}_{\mathrm{t}}$ indicates the change in the log nominal exchange rate between period $\mathrm{t}-1$ and $\mathrm{t}, \mathrm{I}_{1}$ the domestic nominal interest rate and $\mathrm{I}_{\mathrm{t}-1}^{*}$ the foreign nominal interest rate in period $\mathrm{t}-1$. Under rational expectations, uncovered interest parity ${ }^{2}$ implies that $\beta=1$. However, an abundance of empirical evidence rejects uncovered interest parity or forward rate unbiasedness, see for example surveys by Hodrick (1987), Froot \& Thaler (1990) and Engel (1996). Froot \& Thaler (1990) conclude that the UIP-test-coefficient $\beta$ found in the empirical literature is always smaller than the theoretically implied value of one, the average value being -0.88. In a more recent study, Chinn \& Meredith (2002) find an average value of -0.8 for 3-, 6- and 12-month horizons for the period 1980-I to 2000-I. However, Baillie \& Bollerslev (2000) and Flood \& Rose (2002) show through five year rolling regressions that in the 1990s the UIP-test-coefficient is often positive and sometimes even larger than one, but still significantly different from one and also very heterogeneous across countries. Meredith \& Ma (2002) show that during the second half of the 1990s, the UIP-test-coefficient drops below zero again in rolling regressions.

\footnotetext{
${ }^{1}$ Under covered interest parity, the forward premium $f_{t-1}-S_{t-1}$ is identical to the interest differential $I_{t-1}-I_{t-1}^{*}$. Hence tests of uncovered interest parity and tests of forward rate unbiasedness are equivalent.

${ }^{2}$ The possibility of a constant risk premium is captured by $\rho$.
} 
Since the empirical test in (1) is based on the joint hypothesis of rational expectations and a constant risk premium, two obvious explanations for the forward premium puzzle are expectational error and the existence of a time-varying risk premium. Froot \& Frankel (1989) use survey data on exchange rate expectations to decompose the deviations from UIP into deviations caused by expectational error and deviations caused by a time-varying risk premium. They find that by far the largest part of deviations from UIP are caused by expectational error, while the time-varying risk premium plays a minor role. However, the results of MacDonald \& Torrance (1989), Taylor (1989) and Cavaglia et al. (1994) indicate an important role for a time-varying risk premium, in addition to expectational error. A theoretical study by Jeanne \& Rose (2002) shows that in a flexible price monetary model the UIP test coefficient is decreasing in the share of noise traders in the market.

Small sample bias ('peso problem') and endogeneity bias (related to monetary policy) play an additional role in explaining outcomes of UIP tests. Flood \& Rose (1996) estimate the effect of the peso problem on the UIP-test-coefficient to be minor, about -0.5 , hence it does not explain the considerably larger deviations from UIP, which especially occur for freely floating exchange rates (which face a smaller peso problem). More recently, Flood \& Rose (2002) find negative values for the UIP-test-coefficients for fixed and flexible exchange rates, but positive values for crisis countries that have experienced a regime shift, indicating that the reduction of the peso problem has improved the performance of UIP for crisis countries. As a matter of fact, Flood \& Rose (1996) even find values considerably larger than one in UIPtests for crisis countries, such as Finland and Malaysia (2.56 and 2.07 at the three month horizon). Chinn \& Frankel (2002) find a value of 1.214 for the crisis-ridden EMS-currencies and -1.483 for non-European currencies at the three month horizon. Flood \& Taylor (1997) find that UIP performs much better at longer horizons, which is consistent with short run monetary policy endogeneity bias (McCallum (1994)). Chinn \& Meredith (2002) and Meredith \& Ma (2002) generalize the McCallum model to show that monetary policy responses to exchange rate movements contribute to the failure of short run UIP.

In this paper we try to explain the forward premium puzzle by investigating the implications of another stylized fact of foreign exchange: the rejection of rational (and static) expectations in survey data on exchange rate expectations and the support for extrapolative, adaptive and regressive expectations at horizons (1,3,6,12 months) at which uncovered interest parity is usually tested (Bank of Japan (1989), Cavaglia et al. (1993), Dominguez (1986), Frankel \& Froot (1987a) and (1987b), Froot \& Frankel (1989) and (1990), Ito (1990)). 
The survey evidence on expectations formation in foreign exchange markets is supported by recent experimental evidence. Bloomfield \& Hales (2002) show that even if subjects know that a time series follows a random walk, they will not hold static expectations (which is the rational expectations solution in this case). Instead their beliefs will switch between a trending regime and a mean-reverting regime, depending on the observed frequency of price reversals. After a high number of reversals, they think they are in a mean-reverting regime, while after a low number of reversals, they think they are in a trending regime. The experimental results are consistent with the model of investor sentiment by Barberis, Shleifer \& Vishny (1998) and confirm that subjects believe in the "law of small numbers" (Tversky \& Kahneman, 1971, Rabin, 2002), a manifestation of the representativeness heuristic (Kahneman \& Tversky, 1973) and overreliance on unreliable data (Griffin \& Tversky, 1992). The tendency to perceive patterns in a random series can also be seen as a form of overconfidence, see for example Glaser, Langer \& Weber (2003).

Belief in mean reversion or trending is also dependent on the time horizon. The survey evidence of Frankel \& Froot (1987b) indicates that traders are more inclined to distributed lag and regressive expectations (mean-reverting expectations mechanisms) for longer horizons, while bandwagon expectations (trend following expectations mechanism) are more important at short horizons. This is confirmed by Taylor \& Allen (1992), who show that foreign exchange dealers consider fundamentalism to be more important for long horizons, while chartism receives a higher weight at short horizons. It is also consistent with evidence of short-term positive autocorrelation and long-term negative autocorrelation of excess returns ${ }^{3}$ (Cutler, Poterba \& Summers (1991), Froot \& Ramadorai (2002)), which in turn can be explained by recent models of short run underreaction and and long run overreaction in asset markets. Hong \& Stein (1999) show that gradually diffusing private information in asset markets (such as order flow in the foreign exchange market, see for example Lyons (1997)) leads to underreaction in the short run from which momentum traders can benefit, causing overreaction in the long run which may be exploited by contrarians. Daniel, Hirshleifer \& Subrahmanyam (1998) argue that overconfidence about private information and selfattribution in processing public information lead to underreaction to public signals - and positive autocorrelation in the short run - and overreaction to private signals, which after a correction causes negative autocorrelation in the long run. Barberis, Shleifer \& Vishny (1998)

\footnotetext{
${ }^{3}$ More precisely: under extrapolative expectations with respect to exchange rate returns, the expected partial autocorrelation in excess returns $\Delta \mathrm{s}_{\mathrm{t}}+\mathrm{I}_{\mathrm{t}-1-\mathrm{I}_{\mathrm{t}-1}}$ is equal to the expected autocorrelation in exchange rate returns $\Delta \mathrm{s}_{\mathrm{t}}$.
} 
suggest that conservatism in updating beliefs leads to underreaction to news with low strength of evidence and high weight of evidence (Griffin \& Tversky (1992)) and positive autocorrelation in the short run, while the representativeness heuristic (Tversky \& Kahneman (1971)) causes overreaction to news with high strength and low weight and - after a correction - negative autocorrelation in the long run.

Learning from forecast errors, i.e. adaptive expectations, also finds strong support from experimental and empirical studies, in addition to survey data. Several experiments provide support for adaptive expectations and reject extrapolative expectations and rational expectations (Schmalensee (1976), Williams (1987), Smith, Suchanek \& Williams (1988), Hey (1994)). An empirical study by Chow (1989) shows that present value models of stock prices and interest rates that are rejected by the data when the rational expectations assumption is imposed, are accepted under adaptive expectations.

To summarize, the experimental and survey evidence suggests that expectations formation may take the form of extrapolative expectations (both bandwagon and distributed lag expectations), adaptive expectations and regressive expectations. The objective of this paper is to investigate the implications of these standard exchange rate expectations mechanisms for the outcomes of uncovered interest parity tests.

Two earlier simulation studies suggest that this is a promising approach to explain the values of uncovered interest parity test coefficients that we find in the empirical literature. Monte Carlo experiments with a representative agent model of forward foreign exchange market equilibrium without a risk premium by Zietz (1995) generate a small negative value for the UIP-test-coefficient $(-0.009)$ in case of static expectations and a positive value of 0.804 for a weighted average of static and rational expectations. De Grauwe et al. (1993) show that a chaotic monetary model with a representative agent who combines chartist and fundamentalist information is able to generate negative UIP-test-coefficients between -2.20 and -1.74 in the absence of a risk premium.

We prove that in a representative agent model with a constant risk premium, the uncovered interest parity test coefficient can be expressed as a function of the parameters of the expectations mechanism and the interest rate processes. We show that these analytic results provide a robust explanation of uncovered interest parity test outcomes, when we take into account the market microstructure through simulations of a multiagent model with a time-varying risk premium. Markets with bandwagon expectations yield positive coefficients, while distributed lag expectations lead to negative coefficients. As the absolute size of the bandwagon or distributed lag expectations parameter shrinks, the absolute size of the UIP- 
test-coefficient increases. Regressive expectations are most likely to generate positive coefficients, which are larger as the expected adjustment towards the fundamental exchange rate decreases. Adaptive expectations tend to exhibit positive coefficients when traders adapt their expectations slowly and yield negative coefficients when learning increases. Our approach offers an explanation of the usual findings of UIP-test-coefficients smaller than one and even smaller than zero and more recent findings for the early 1990s of certain UIP-testcoefficients larger than one. The latter finding is of particular interest, since the noise trader model by Jeanne \& Rose (2002) explains only values smaller than one.

The remainder of this paper is organized as follows. In section 2 we derive the relationship between the value of the UIP-test-coefficient and the parameters of the expectations mechanism and the interest rate processes in a representative agent model with extrapolative, adaptive and regressive expectations and a constant risk premium. Section 3 takes into account the market microstructure by extending the analysis to a multiagent model with a time-varying risk premium. In section 4 we perform uncovered interest parity tests on simulations of the multiagent model for different expectations mechanisms. In section 5 we draw conclusions on the relationship between exchange rate expectations and the outcomes of uncovered interest parity tests.

\section{Representative agent model}

\subsection{Extrapolative expectations}

In this section we develop a theoretical model based on he survey evidence on exchange rate expectations and empirical evidence on the time series properties of interest rates. The first building block of the model are the tests for perfect substitutability in the survey data studies by Frankel \& Froot (1987b) and Froot \& Frankel (1989) that support the following uncovered arbitrage condition:

$$
\Delta \mathrm{s}_{\mathrm{t}+1}^{\mathrm{e}}=\mathrm{I}_{\mathrm{t}}-\mathrm{I}_{\mathrm{t}}^{*}+\pi
$$

where $\pi$ is a risk-related deviation from perfect substitutability that does not change over time. 
The second element is the survey evidence on exchange rate expectations that rejects rational expectations in favor of extrapolative, adaptive and regressive expectations. The final ingredient is the persistence in interest rates found in empirical studies. In a representative agent model with a constant risk premium ${ }^{4}$ and persistent interest rates, the relationship between the extrapolative, adaptive and regressive expectations mechanisms and the outcomes of uncovered interest parity tests can be derived in a straightforward manner.

First consider a situation where the representative agent forms extrapolative expectations (Metzler (1941), Goodwin (1947)):

$\mathrm{s}_{\mathrm{t}+1}^{\mathrm{e}}=(1-\alpha) \mathrm{s}_{\mathrm{t}}+\alpha \mathrm{s}_{\mathrm{t}-1}$

Empirical estimates of $\alpha$ at the three month horizon range from -0.07 to 0.58 (Frankel \& Froot (1987a), (1987b), Bank of Japan (1989), Froot \& Frankel (1990), Cavaglia et al. (1993)). Three cases of this expectations mechanism can be distinguished. If $\alpha>0$, the expected exchange rate is a distributed lag of the observed exchange rate, hence this case is known as 'distributed lag expectations'. By rewriting this expectations mechanism as

$\Delta \mathrm{s}_{\mathrm{t}+1}^{\mathrm{e}}=-\alpha \Delta \mathrm{s}_{\mathrm{t}}$

it is clear that agents with distributed lag expectations expect an exchange rate increase to be followed by a decrease in the future. On the other hand, if $\alpha<0$, agents expect an exchange rate increase to be followed by a further increase in the future. This case is therefore known as 'bandwagon expectations'. Finally, if $\alpha=0$, agents expect the exchange rate to remain at the current level, hence this case is called 'static expectations'. Notice from uncovered interest arbitrage condition (2) that in this case the risk premium must be time-varying and identical to the interest differential. Hence in this section we will assume that $\alpha \neq 0$ for extrapolative expectations traders. As mentioned in the introduction, this assumption is supported by evidence from surveys and experiments. If we combine uncovered interest arbitrage condition (2) with expectations mechanism (4) we obtain

\footnotetext{
${ }^{4}$ Since there is also survey evidence supporting the existence of a time-varying risk premium and heterogeneity in expectations, we will develop a multi-agent model with a time-varying risk premium in the next section.
} 
$\Delta \mathrm{s}_{\mathrm{t}}=-\frac{1}{\alpha}\left(\mathrm{I}_{\mathrm{t}}-\mathrm{I}_{\mathrm{t}}^{*}\right)$

Empirical studies show that interest rates are highly persistent, for example Perron (1988), Rose (1988) and Stock \& Watson (1988) find evidence of a unit root. However, Campbell \& Perron (1991), Cochrane (1991) and DeJong et al. (1992) argue that unit root tests have low power against stationary alternatives in small samples. Wu \& Zhang (1996) show that it is more likely that interest rates are highly autocorrelated but stationary. We can represent this property by a first order autoregressive process:

$\mathrm{I}_{\mathrm{t}}=\theta \mathrm{I}_{\mathrm{t}-1}+\eta_{\mathrm{t}}$

$\mathrm{I}_{\mathrm{t}}^{*}=\theta^{*} \mathrm{I}_{\mathrm{t}-1}^{*}+\eta_{\mathrm{t}}^{*}$

For simplicity, we assume identical parameters $0<\theta=\theta *<1$. Now exchange rate returns can be expressed in terms of the lagged interest rate differential as follows:

$$
\Delta \mathrm{s}_{\mathrm{t}}=-\frac{\pi}{\alpha}-\frac{\theta}{\alpha}\left(\mathrm{I}_{\mathrm{t}-1}-\mathrm{I}_{\mathrm{t}-1}^{*}\right)-\frac{1}{\alpha}\left(\eta_{\mathrm{t}}-\eta_{\mathrm{t}}^{*}\right)
$$

This suggests that for a given interest rate parameter $\theta$, there is a direct link between the estimated coefficient of the uncovered interest parity test and the prevailing expectations mechanism, as shown in figure 1. The sign and the size of the expectations parameter $\alpha$ determines the sign and size of the UIP-test-coefficient $\beta$ found in empirical studies. From another perspective, the estimated coefficient can be used to infer the prevailing expectations parameter. Notice that values of the UIP-test-coefficient between -1 and 1 require an expectations parameter $\alpha$ that is larger in size than the autocorrelation $\theta$ of the interest rate differential process. This outcome is not very likely, as the empirical evidence suggest that $\theta$ is in the neighborhood of unity (Perron, 1988, Rose, 1988, Stock \& Watson, 1988, Wu \& Zhang, 1996) and survey data estimates (Frankel and Froot, 1987a, 1987b, Bank of Japan, 1989, Froot and Frankel, 1990, Cavaglia et al., 1993) put $\alpha$ between -0.10 and 0.60 . Hence distributed lag expectations are able to explain the large negative values of UIP-test- 
coefficients that are typical for empirical studies, while bandwagon expectations offer an explanation for more recent findings of values larger than one for the early 1990s.

Figure 1: Ex trapolative expectations and uncovered interest parity test coefficients

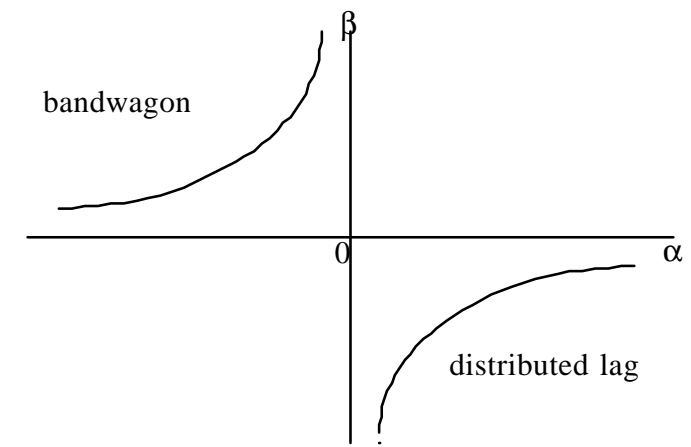

\subsection{Adaptive expectations}

Adaptive expectations (Cagan (1956), Nerlove (1958)) played an important role in macroeconomics before the 1970s when rational expectations (Muth (1961)) became the standard assumption (Redman (1992)). Agents are said to hold adaptive expectations if they adjust their previous exchange rate expectations in the direction of the most recently observed exchange rate:

$$
\mathrm{s}_{\mathrm{t}+1}^{\mathrm{e}}=(1-\alpha) \mathrm{s}_{\mathrm{t}}+\alpha \mathrm{s}_{\mathrm{t}}^{\mathrm{e}} \quad(0<\alpha<1)
$$

Empirical estimates of $\alpha$ at the three month horizon range from 0.07 to 0.19 (Frankel and Froot, 1987a, 1987b, Cavaglia et al., 1993). Adaptive expectations can be rewritten by backward substitution as

$\mathrm{s}_{\mathrm{t}+1}^{\mathrm{e}}=(1-\alpha) \mathrm{s}_{\mathrm{t}}+\alpha(1-\alpha) \mathrm{s}_{\mathrm{t}-1}+\alpha^{2} \mathrm{~s}_{\mathrm{t}-1}^{\mathrm{e}}$

hence 
$\Delta \mathrm{s}_{\mathrm{t}+1}^{\mathrm{e}}=-\alpha \Delta \mathrm{s}_{\mathrm{t}}+\alpha^{2}\left(\mathrm{~s}_{\mathrm{t}-1}^{\mathrm{e}}-\mathrm{s}_{\mathrm{t}-1}\right)$

With uncovered arbitrage condition (2) and autoregressive interest rate processes (6) and (7) this implies

$$
\Delta \mathrm{s}_{\mathrm{t}}=-\frac{\pi}{\alpha}-\frac{\theta}{\alpha}\left(\mathrm{I}_{\mathrm{t}-1}-\mathrm{I}_{\mathrm{t}-1}^{*}\right)+\alpha\left(\mathrm{s}_{\mathrm{t}-1}^{\mathrm{e}}-\mathrm{s}_{\mathrm{t}-1}\right)-\frac{1}{\alpha}\left(\eta_{\mathrm{t}}-\eta_{\mathrm{t}}^{*}\right)
$$

The exchange rate return is a function of the lagged interest rate differential, the lagged expectational error and the interest rate innovations. The lagged expectational error is a function of the entire history of exchange rates $\mathrm{s}_{\mathrm{t}-1}, \mathrm{~s}_{\mathrm{t}-2}, \ldots$ as can be shown by backward substitution. The uncovered interest parity test coefficient under adaptive expectations will tend to be negative, as interest rates exhibit positive autocorrelation. For larger values of $\alpha$, the coefficient will be smaller in size (see figure 2). However, the hgged expectational error causes an omitted variable bias in the UIP-test-coefficient. Notice from the coefficients of the first two terms that for larger values of the adaptive expectations parameter $\alpha$, the omitted variable bias grows.

Figure 2: Adaptive expectations and uncovered interest parity test coefficients

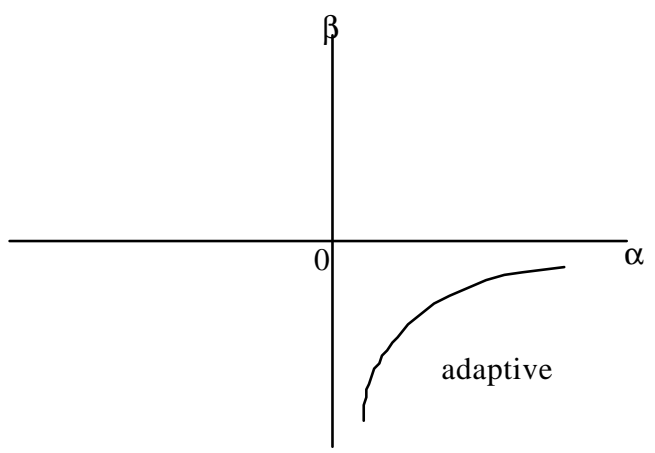




\subsection{Regressive expectations}

Regressive expectations play a crucial role in the overshooting model of Dornbusch (1976) and can be traced back to Keynes (1936) who suggested that financial markets expect interest rates to regress to a 'normal' level. Agents are characterized by regressive expectations if they expect the (logarithm of the) future exchange rate to move in the direction of some fundamental or long run equilibrium value $\mathrm{q}$ :

$\Delta \mathrm{s}_{\mathrm{t}+1}^{\mathrm{e}}=\alpha\left(\mathrm{q}_{\mathrm{t}}-\mathrm{s}_{\mathrm{t}}\right) \quad(\alpha>0)$

Positive estimates of $\alpha$ for regressive expectations at the three month horizon range from 0.01 to 0.09 (Frankel and Froot, 1987a, 1987b, Bank of Japan, 1989, Froot and Frankel, 1990). If we assume that fundamentals follow a random walk

$\mathrm{q}_{\mathrm{t}}=\mathrm{q}_{\mathrm{t}-1}+\mathrm{v}_{\mathrm{t}} \quad\left(\mathrm{E}\left[\mathrm{v}_{\mathrm{t}}\right]=0\right)$

then from uncovered interest arbitrage condition (2) it follows that

$\alpha\left(\mathrm{q}_{\mathrm{t}}-\mathrm{s}_{\mathrm{t}}\right)=\mathrm{I}_{\mathrm{t}}-\mathrm{I}_{\mathrm{t}}^{*}+\pi$

and one period earlier

$\alpha\left(\mathrm{q}_{\mathrm{t}-1}-\mathrm{s}_{\mathrm{t}-1}\right)=\mathrm{I}_{\mathrm{t}-1}-\mathrm{I}_{\mathrm{t}-1}^{*}+\pi$

If we subtract (16) from (15), substitute (14) and rearrange we obtain

$$
\Delta s_{t}=\frac{1}{\alpha}\left(I_{t-1}-I_{t-1}^{*}\right)-\frac{1}{\alpha}\left(I_{t}-I_{t}^{*}\right)+v_{t}
$$

Notice that the risk term $\pi$ has dropped out of the equation. If we assume autoregressive interest rate time series given by (6) and (7) with identical parameters $\theta=\theta^{*}$, we obtain: 


$$
\Delta \mathrm{s}_{\mathrm{t}}=\frac{1-\theta}{\alpha}\left(\mathrm{I}_{\mathrm{t}-1}-\mathrm{I}_{\mathrm{t}-1}^{*}\right)+\frac{1}{\alpha}\left(\eta_{\mathrm{t}}^{*}-\eta_{\mathrm{t}}\right)+\mathrm{v}_{\mathrm{t}}
$$

The correlation between current exchange rate returns and lagged interest differentials will tend to be positive, since $\alpha>0$ and $\theta<1$. Regressive expectations lead to positive UIP-testcoefficients, which are smaller as the regressive expectations parameter $\alpha$ increases, see figure 3.

Figure 3: Regressive expectations and uncovered interest parity test coefficients

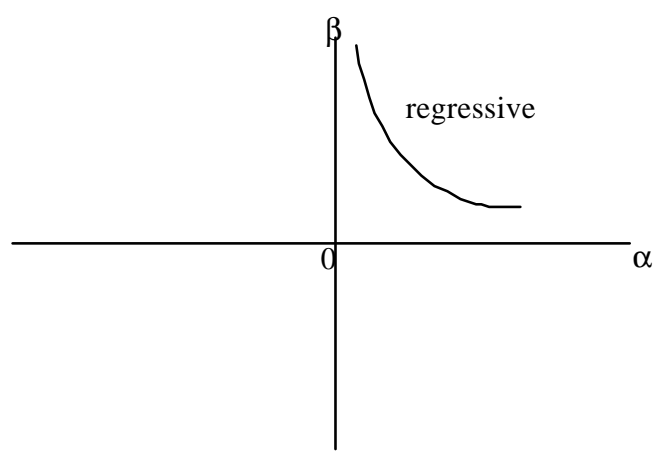

\section{Market microstructure}

\subsection{Heterogeneous expectations}

The market microstructure literature is based on the idea that the representative agent approach is unable to explain essential features of foreign exchange markets - such as the huge volume of trade, excessive market volatility and persistent deviations from macroeconomic fundamentals - which are better explained by heterogeneous agents (Frankel et al. (1997)). Evidence from survey data points to considerable individual heterogeneity in the expectations formation of traders (Ito (1990), Taylor \& Allen (1992) and MacDonald \& Marsh (1996)). Since expectations formation is the crucial ingredient in the explanation of uncovered interest parity test outcomes developed in this paper, we have to take this aspect of 
the market microstructure into account ${ }^{5}$. In order to test the robustness of the analytic results derived in section 2, we therefore extend the analysis to a microeconomic model consisting of heterogeneous risk-averse agents who perform uncovered interest arbitrage based on their exchange rate expectations and a mean-variance utility function. We allow for heterogeneity with respect to exchange rate expectations, risk aversion, initial endowments of domestic and foreign interest-bearing assets and the currency in which investment performance is evaluated. This multi-agent model also generates a time-varying risk premium, conform evidence from survey data by MacDonald \& Torrance (1989), Taylor (1989) and Cavaglia et al. (1994), which stands in contrast with the findings of a constant risk premium by Frankel \& Froot (1987b) and Froot \& Frankel (1989) discussed in section 2.

\subsection{Multi-agent model}

Assume that there are $\mathrm{m}$ domestic traders and $\mathrm{n}$ foreign traders operating in a financial system consisting of a one period domestic money market with interest rate $\mathrm{I}_{\mathrm{t}}$, a one period foreign money market with interest rate $\mathrm{I}_{\mathrm{t}}^{*}$ and a spot foreign exchange market with exchange rate $\mathrm{S}$.

Let $\mathrm{E}_{\mathrm{t}, \mathrm{i}}\left(\mathrm{S}_{\mathrm{t}+1}\right)$ denote the expectation of domestic trader $\mathrm{i}$ in period $\mathrm{t}$ concerning the future exchange rate $S_{t+1}$ and let $\operatorname{Var}_{t, i}\left(S_{t+1}\right)$ be the variance of $S_{t+1}$ that domestic trader $i$ anticipates in period t. Based on the expected utility function of Newbery (1988), the optimal foreign currency position of domestic trader i can be derived as

$Y_{t, i}=\frac{\left(1+I_{t}^{*}\right) E_{t, i}\left(S_{t+1}\right)-\left(1+I_{t}\right) S_{t}}{\left(1+I_{t}^{*}\right)^{2} \gamma_{t, i} \operatorname{Var}_{t, i}\left(S_{t+1}\right)}$

where the second order condition requires the parameter of absolute risk aversion $\gamma_{t, \mathrm{i}}$ to be positive. The expectations of domestic traders are specified in their most general form as follows:

$\mathrm{E}_{\mathrm{t}, \mathrm{i}}\left(\mathrm{S}_{\mathrm{t}+1}\right)=\mathrm{S}_{\mathrm{t}}^{1-\alpha_{\mathrm{t}, \mathrm{i}}} \mathrm{Z}_{\mathrm{t}, \mathrm{i}} \alpha_{\mathrm{t}, \mathrm{i}}$

\footnotetext{
${ }^{5}$ See the survey of the literature by Sarno \& Taylor (2002) for the role of expectations in foreign exchange market microstructure.
} 
where $\mathrm{Z}_{\mathrm{t}, \mathrm{i}}=\mathrm{S}_{\mathrm{t}-1}$ in case of extrapolative expectations, $\mathrm{Z}_{\mathrm{t}, \mathrm{i}}=\mathrm{E}_{\mathrm{t}-1, \mathrm{i}}\left(\mathrm{S}_{\mathrm{t}}\right)$ in case of adaptive expectations and $\mathrm{Z}_{\mathrm{t}, \mathrm{i}}=\mathrm{Q}_{\mathrm{t}}$ in case of regressive expectations. Traders do not anticipate volatility clusters, conform empirical evidence on horizons at which uncovered interest parity tests are usually performed (1, 3, 6, 12 months). For example, Baillie \& Bollerslev (1989) show that $\mathrm{ARCH}$ effects in daily and weekly exchange rates do not appear in monthly exchange rates. Therefore we assume that the anticipated variance of $S_{t+1} / S_{t}$ does not change over time:

$\operatorname{Var}_{\mathrm{t}, \mathrm{i}}\left(\mathrm{S}_{\mathrm{t}+1}\right)=\omega_{\mathrm{t}, \mathrm{i}} \mathrm{S}_{\mathrm{t}}^{2}$

With analogous definitions of expectations and risk aversion for foreign trader $\mathrm{j}$, the implicit expression for the equilibrium exchange rate follows from (19), (20) and (21) as:

$$
\begin{aligned}
& \sum_{i=1}^{m} \frac{Z_{t, i}^{\alpha_{t, i}}}{\left(1+I_{t}^{*}\right) \gamma_{t, i} \omega_{t, i}} S_{t}^{-1-\alpha_{t, i}}-\sum_{j=1}^{n} \frac{Z_{t, j}^{*}{ }^{-\alpha_{t, j}^{*}}}{\left(1+I_{t}\right) \gamma_{t, j}^{*} \omega_{t, j}^{*-1}} S_{t}^{\alpha_{t, j}^{*}}+ \\
& +\left(\sum_{j=1}^{n} A_{t, j}^{*}-\sum_{i=1}^{m} \frac{1+I_{t}}{\left(1+I_{t}^{*}\right)^{2} \gamma_{t, i} \omega_{t, i}}\right) S_{t}^{-1}+\left(\sum_{j=1}^{n} \frac{1+I_{t}^{*}}{\left(1+I_{t}\right)^{2} \gamma_{t, j}^{*} \omega_{t, j}^{*-1}}-\sum_{i=1}^{m} B_{t, i}\right)=0
\end{aligned}
$$

where $\mathrm{B}_{t, \mathrm{i}}$ is the foreign currency endowment of domestic trader $\mathrm{i}$ in period $\mathrm{t}$ and $\mathrm{A}_{\mathrm{t}, \mathrm{j}}$ the domestic currency endowment of foreign trader $\mathrm{j}$. In the simulations we will assume that the prevailing equilibrium exchange rate is selected by a Walrasian auctioneer who uses the Newton-Raphson algorithm with initial value $S_{t-1}$ to compute the nearest real-valued root of the polynomial of equation (22).

\subsection{Simulations}

The purpose of the simulations is to test the robustness of the relationship between the prevailing expectations mechanism and the outcome of the uncovered interest parity test.

\footnotetext{
${ }^{6}$ This model is based on Marey (2004), to which the reader is referred for details.
} 
Therefore we will assume that during each simulation all traders use the same variable $\mathrm{Z}_{\mathrm{i}}=\mathrm{Z}_{\mathrm{t}}$ to form expectations with a time-invariant weight $\alpha_{t, i}=\alpha_{i}$ that is different for each trader. In each experiment we draw $\alpha_{i}$ from a lognormal distribution with expected value $\alpha$. In this way we can corroborate the analytical results derived in section 2 , by performing simulations of bandwagon expectations markets $\left(\mathrm{Z}_{\mathrm{t}}=\mathrm{S}_{\mathrm{t}-1}, \alpha<0\right)$, distributed lag expectations markets $\left(\mathrm{Z}_{\mathrm{t}}=\right.$ $\left.\mathrm{S}_{\mathrm{t}-1}, \alpha>0\right)$, adaptive expectations markets $\left(\mathrm{Z}_{\mathrm{t}}=\mathrm{E}_{\mathrm{t}-1}\left(\mathrm{~S}_{\mathrm{t}}\right), \alpha>0\right)$ and regressive expectations markets $\left(Z_{t}=Q_{t}, \alpha>0\right)$ for different values of $\alpha$. Each simulation will involve 200 agents: $\mathrm{m}$ $=100$ domestic traders and $\mathrm{n}=100$ foreign traders. The duration of each simulation is 100 periods, which corresponds with 25 years of quarterly observations ${ }^{7}$. The initial values and evolution of wealth, risk aversion, anticipated variance, expectations parameters, interest rates and the fundamental exchange rate are as described in Marey (2004), with the exception of the first order autocorrelation parameter of domestic and foreign interest rates, which we set here at 0.98 .

\section{Uncovered interest parity tests on simulations}

Experiments with each market type discussed in section 3 are performed for different values of the expectations parameter $\alpha$. For each $\alpha, 100$ simulations with a duration of 100 periods are run and the uncovered interest parity test is performed on each simulated time series:

$$
\Delta s_{t}=\rho+\beta\left(I_{t-1}-I_{t-1}^{*}\right)+\varepsilon_{t}
$$

Hence for each market type and each $\alpha, 100$ estimates of the UIP-test-coefficient $\beta$ are obtained. Each simulation is characterized by a different set of initial values and evolutions of exogenous variables. Hence each simulation represents a different realization of heterogeneity and a different path of the time-varying risk premium. Tables 1-4 show the results of the uncovered interest parity tests, in particular the mean value of the estimated $\beta$ over 100 simulations for each $\alpha$, the standard deviation and the 5th and 95th pe rcentiles.

\footnotetext{
${ }^{7}$ The survey evidence is most extensive for the three month horizon. The empirical estimates of $\alpha$ at this horizon mentioned in section 2 will be used as a criterion for the range of values of $\alpha$ simulated in section 4 .
} 
For the bandwagon expectations marke ${ }^{8}$, we consider values of the average $\alpha$ between -0.25 and -0.05 . As table 1 shows, bandwagon expectations $\alpha<0$ ) generate positive values for $\beta$. In fact, the lowest value for all simulations is $1.70(\alpha=-0.25)$. In addition, when $\alpha$ moves towards 0 the value of $\beta$ tends to increase. The mean value of $\beta$ shows a monotonous increase as a function of $\alpha$, the same holds for the 5th and 95th percentiles. In other words, the simulations confirm the robustness of the analytical results in subsection 2.1. The percentiles also indicate that, depending on the risk premium and trader heterogeneity, a market with an $\alpha$ closer to zero than another market may very well have a lower value of $\beta$. Hence one cannot simply infer the underlying expectations parameter $\alpha$ from an estimated coefficient $\beta$. However, higher positive values of $\beta$ are more likely to be caused by extrapolative expectations with negative $\alpha$ closer to 0 . Table 1 gives an indication of the probability distribution of $\beta$, where the uncertainty is caused by the time-varying risk premium and trader heterogeneity. Bandwagon expectations offer an explanation for recent findings for the early 1990s of UIP-test-coefficients larger than one, when the peso problem is accounted for (as is the case with our simulations), in particular for crisis countries.

Table 1: UIP-test-coefficients in case of bandwagon expectations

\begin{tabular}{|c|c|c|c|c|}
\hline$\alpha$ & Mean value of $\beta$ & $\begin{array}{c}\text { Standard deviation } \\
\text { of } \beta\end{array}$ & $5^{\text {th }}$ percentile of $\beta$ & percentile of $\beta$ \\
\hline-0.25 & 2.38 & 0.24 & 1.97 & 2.78 \\
\hline-0.20 & 2.82 & 0.31 & 2.25 & 3.32 \\
\hline-0.15 & 3.62 & 0.49 & 2.79 & 6.45 \\
\hline-0.10 & 4.88 & 0.71 & 3.55 & 11.12 \\
\hline-0.05 & 8.62 & 1.45 & 6.21 & 6.08 \\
\hline
\end{tabular}

For the distributed lag expectations market, we consider values of the average $\alpha$ between 0.10 and 0.60 . From table 2 we see that distributed lag expectations $(\alpha>0)$ lead to negative values for $\beta$. Actually, the highest value for $\beta$ is -2.11 (for $\alpha=0.50$ ). In addition, higher values of expectations parameter $\alpha$ cause an upward shift in the mean value of the

\footnotetext{
${ }^{8}$ As mentioned in subsection 2.1, empirical estimates of $\alpha$ for extrapolative expectations range from -0.07 to 0.58 .

${ }^{9}$ See previous footnote.
} 
estimated values of UIP-test-coefficient $\beta$. These mean values fall within the spectrum of estimates of empirical studies. The simulations show that the analytical results derived in subsection 2.1 are robust and that distributed lag expectations are able to explain the usual findings of negative UIP-test-coefficients, in particular for freely floating exchange rates.

Table 2: UIP-test-coefficients in case of distributed lag expectations

\begin{tabular}{|c|c|c|c|c|}
\hline$\alpha$ & Mean value of $\beta$ & $\begin{array}{c}\text { Standard deviation } \\
\text { of } \beta\end{array}$ & $5^{\text {th }}$ percentile of $\beta$ & 95 \\
\hline 0.10 & -7.81 & 1.49 & -10.37 & -5.45 \\
\hline 0.20 & -5.30 & 1.12 & -7.22 & -3.98 \\
\hline 0.30 & -4.19 & 0.59 & -5.23 & -3.29 \\
\hline 0.40 & -3.49 & 0.59 & -4.41 & -2.57 \\
\hline 0.50 & -2.99 & 0.41 & -3.68 & -2.39 \\
\hline
\end{tabular}

For the adaptive expectations market ${ }^{10}$, we consider values of the average $\alpha$ between 0.05 and 0.30. Table 3 shows that, unlike bandwagon and distributed expectations, the adaptive expectations markets are able to generate both negative and positive values for $\beta$, in particular when the expectations parameter is large enough $(\alpha \geq 0.20)$. The mean value of $\beta$ increases as a function of $\alpha$, as do the 5th and 95th percentiles (except for the 95th percentile when $\alpha$ moves from 0.25 to 0.30 ). Hence as the weight $\alpha$ given to the previous forecast increases, so does the value of $\beta$. From a different perspective, as the weight $1-\alpha$ given to the current exchange rate increases, i.e. learning increases, the value of $\beta$ decreases. In subsection 2.2 we expected to find negative mean values for $\beta$, with a possible exception for larger values of $\alpha$ because of the growing omitted variable bias. The simulations show that the omitted variable bias starts affecting the UIP-test-coefficients at $\alpha=0.20$ by generating a number of positive values of $\beta$, while at $\alpha=0.25$ even the mean value of $\beta$ turns positive. Adaptive expectations are able to explain a wide spectrum of outcomes for UIP-tests: (large) negative values, positive values smaller than one and even values larger than one. 
Table 3: UIP-test-coefficients in case of adaptive expectations

\begin{tabular}{|c|c|c|c|c|}
\hline$\alpha$ & Mean value of $\beta$ & $\begin{array}{c}\text { Standard deviation } \\
\text { of } \beta\end{array}$ & $5^{\text {th }}$ percentile of $\beta$ & 95 \\
\hline 0.05 & -11.06 & 3.00 & -15.91 & -6.19 \\
\hline 0.10 & -6.09 & 1.67 & -9.18 & -3.42 \\
\hline 0.15 & -4.62 & 1.03 & -6.40 & -3.22 \\
\hline 0.20 & -2.51 & 2.25 & -5.04 & 1.51 \\
\hline 0.25 & 0.29 & 1.44 & -2.68 & 1.96 \\
\hline 0.30 & 0.18 & 1.18 & -2.02 & 1.92 \\
\hline
\end{tabular}

For the regressive expectations market ${ }^{11}$, we consider values of the average $\alpha$ between 0.01 and 0.10 . From table 4 we see that the mean values for $\beta$ are all positive. However, a small number of negative values are found for all $\alpha$ (the largest being -1.16 for $\alpha=0.03$ ), except 0.01 and 0.06 . The mean $\beta$ falls as the expected speed of adjustment towards the fundamental exchange rate $\alpha$ increases, except between 0.04 and 0.05 and between 0.09 and 0.10. Regressive expectations parameter values of 0.08 and higher are more likely to generate UIP-test-coefficients between zero and one, while lower values of $\alpha$ offer an explanation for recent findings of UIP-test-coefficients larger than 1 . The overall picture indicates that the analytical results in subsection 2.3 are fairly robust.

Table 4: UIP-test-coefficients in case of regressive expectations

\begin{tabular}{|c|c|c|c|c|}
\hline$\alpha$ & Mean value of $\beta$ & $\begin{array}{c}\text { Standard deviation } \\
\text { of } \beta\end{array}$ & $5^{\text {th }}$ percentile of $\beta$ & percentile of $\beta$ \\
\hline 0.01 & 5.43 & 3.08 & 1.66 & 11.71 \\
\hline 0.02 & 3.28 & 1.86 & 1.20 & 4.87 \\
\hline 0.03 & 2.40 & 1.39 & 0.79 & 3.56 \\
\hline 0.04 & 1.60 & 0.97 & 0.25 & 3.66 \\
\hline 0.05 & 1.66 & 1.13 & 0.25 & 2.97 \\
\hline 0.06 & 1.38 & 0.80 & 0.31 & 2.18 \\
\hline 0.07 & 1.09 & 0.65 & 0.09 & 2.05 \\
\hline 0.08 & 0.91 & 0.61 & -0.05 & 1.95 \\
\hline 0.09 & 0.85 & 0.70 & -0.02 & 2.12 \\
\hline
\end{tabular}

\footnotetext{
${ }^{10}$ From subsection 2.2 we know that empirical estimates of $\alpha$ range from 0.07 to 0.19 .

${ }^{11}$ In subsection 2.3 we established that positive estimates of $\alpha$ for regressive expectations range from 0.01 to 0.09 .
} 
The simulations confirm that the analytical results derived in section 2 offer an explanation of uncovered interest parity test outcomes that is robust with respect to trader heterogeneity and a time-varying risk premium. The 5th and 95th percentiles of UIP-testcoefficients generated by the expectations mechanisms simulated in this paper are summarized in figure 4. The (often large) negative values for UIP-test-coefficients frequently found in empirical studies are best explained by adaptive expectations with fast learning and distributed lag expectations. Positive values smaller than one are most likely explained by regressive expectations and adaptive expectations with slow learning. Recent findings of UIPtest-coefficients larger than one for the early 1990s are best explained by bandwagon expectations and regressive expectations. Notice that until recently (Flood \& Rose (1996)), such large positive UIP-test-coefficients were 'novel facts', for example Froot \& Thaler (1990) conclude that empirical studies always yield coefficients smaller than one. Our expectational error approach offers the first explanation of UIP-test-coefficients larger than one.

Figure 4: Uncovered interest parity test coefficients and expectations mechanisms

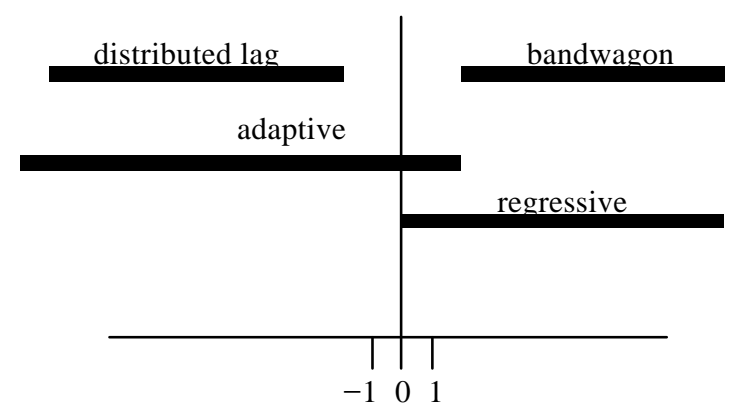




\section{Conclusion}

In this paper we show that there is a relationship between the variables and parameters of the prevailing expectations mechanism in the foreign exchange market and the sign and size of coefficients of uncovered interest parity tests. Bandwagon expectations lead to positive values for the uncovered interest parity test coefficients and are able to explain recent findings for the early 1990s of UIP-test-coefficients larger than one, in particular for crisis countries. When the size of the bandwagon expectations parameter shrinks, the UIP-test-coefficients increase. Distributed lag expectations are able to explain the usual findings of negative UIP-testcoefficients, in particular for freely floating exchange rates. Smaller values of the distributed lag expectations parameter lead to larger negative UIP-test-coefficients. Adaptive expectations are able to generate a variety of outcomes for UIP-tests: the usual (often large) negative values and positive values smaller than one and the more recently observed values larger than one. A higher speed of learning leads to lower values of the UIP-test-coefficient. Regressive expectations explain both positive values between zero and one, and recent findings for the early 1990s of UIP-test-coefficients larger than one. A higher degree of fundamentalism leads to smaller values of the UIP-test-coefficient.

Having determined which outcome for uncovered interest parity tests is most likely when a certain expectations mechanism prevails, the next question is under what circumstances does a certain expectations mechanism prevail in the foreign exchange market? The evidence from experimental and survey data (Bloomfield \& Hales (2002), Frankel \& Froot (1987b), Taylor \& Allen (1992)) suggests that bandwagon expectations are more likely in periods with few price reversals and at higher frequencies (short horizons), while distributed lag expectations and regressive expectations are more likely in periods with many price reversals and at lower frequencies (long horizons).

Another issue is that different expectations mechanisms may be at work simultaneously. In this paper we consider markets consisting of traders with different use of information $\alpha_{\mathrm{i}}$, but identical sources of information $\mathrm{Z}_{\mathrm{t}}$. This allows us to investigate the effects of the various standard expectations mechanisms on the outcomes of uncovered interest parity tests. However, there is evidence that foreign exchange market participants combine different expectations mechanisms, in particular chartist and fundamentalist methods (Taylor \& Allen (1992)). Hence further study could shed light on the relationship between the 
variables and parameters of these hybrid expectations mechanisms and the outcomes of uncovered interest parity tests.

\section{References}

Baillie, R.T. \& T. Bollerslev, The message in daily exchange rates: a conditionatvariance tale, Journal of Business and Economic Statistics 7 (1989): 297-305

Baillie, R.T. \& T. Bollerslev, The forward premium anomaly is not as bad as you think, Journal of International Money and Finance 19 (2000): 471-488

Bank of Japan, Research and Statistics Department, External balance adjustment and monetary policy management under international private capital flows, Bank of Japan, Tokyo, Japan (1989)

Barberis, N., A. Shleifer \& R. Vishny, A model of investor sentiment, Journal of Financial Economics 49 (1998): 307-343

Bloomfield, R. \& J. Hales, Predicting the next step of a random walk: experimental evidence of regime-shifting beliefs, Journal of Financial Economics 65 (2002): 397-414

Cagan, P.D., The monetary dynamics of hyperinflation, In: Studies in the Quantity Theory of Money, ed. by M. Friedman, University of Chicago Press, Chicago (1956)

Campbell, J.Y. \& P. Perron, Pitfalls and opportunities: what macroeconomists should know about unit roots, In: NBER Macroeconomic Annual, Cambridge, MIT Press (1991): 141-201

Cavaglia, S., W.F.C. Verschoor \& C.C.P. Wolff, Further evidence on exchange rate expectations, Journal of International Money and Finance 12 (1993): 78-98

Cavaglia, S.M.F.G., W.F.C. Verschoor \& C.C.P. Wolff, On the biasedness of forward foreign exchange rates: irrationality or risk premia?, Journal of Business 67 (1994): 321-343

Chinn, M.D. \& Frankel, J.A., More survey data on exchange rate expectations: more currencies, more horizons, more tests, in: Allen, W. \& Dickinson, D. (eds), Monetary policy, capital flows and financial market developments in the era of financial globalisation: essays in honour of Max Fry, Routledge, (2002): 145-167

Chinn, M.D. \& Meredith, G., Testing uncovered interest parity at short and long horizons during the post Bretton Woods era, mimeo (2002)

Chow, G.C., Rational versus adaptive expectations in present value models, Review of Economics and Statistics 71 (1989): 376-384 
Cochrane, J.H., A critique of the application of unit root tests, Journal of Economic Dynamics and Control 15 (1991): 275-284

Cutler, D.M., J.M. Poterba \& L.H. Summers, Speculative dynamics, Review of Economic Studies 58 (1991): 529-546

Daniel, K., D. Hirshleifer \& A. Subrahmanyam, Investor psychology and security market under- and overreactions, Journal of Finance 53 (1998): 1839-1885

De Grauwe, P., Dewachter, H. \& Embrechts, M., Exchange Rate Theory: Chaotic Models of Foreign Exchange Markets, Blackwell, Oxford, U.K. (1993)

DeJong, D.N., J.C. Nankervis, N.E. Savin \& C.H. Whiteman, The power problems of unit root tests in time series with autoregressive errors, Journal of Econometrics 53 (1992): 323342

Dominguez, K.N., Are foreign exchange forecasts rational? New evidence from survey data, Economics Letters 21 (1986): 277-282

Dornbusch, R., Expectations and exchange rate dynamics, Journal of Political Economy 84 (1976): 1161-1176

Engel, C., The forward discount anomaly and the risk premium: a survey of recent evidence, Journal of Empirical Finance 3 (1996): 123-192

Flood, R.P. \& Rose, A.K., Fixes: of the forward discount puzzle, Review of Economics and Statistics, Vol. 78, (1996): 748-752

Flood, R.P. \& Rose, A.K., Uncovered interest parity in crisis, IMF Staff Papers, Vol. 49, (2002): 252-266

Flood, R.P. \& M.P. Taylor, Exchange rate economics: What's wrong with the conventional macro approach? In: The Microstructure of Foreign Exchange Markets (1997): 261-294, J.A. Frankel, G. Galli \& A. Giovannini (eds.), University of Chicago Press.

Frankel, J.A. \& K.A. Froot, Using survey data to test standard propositions regarding exchange rate expectations, American Economic Review 77 (1987a): 133-153

Frankel, J.A. \& K.A. Froot, Short-term and long-term expectations of the yen/dollar exchange rate: evidence from survey data, Journal of the Japanese and International Economies 1 (1987b): 249-274

Frankel, J.A., G. Galli \& A. Giovannini, Introduction. In: The Microstructure of Foreign Exchange Markets (1997): 261-294, J.A. Frankel, G. Galli \& A. Giovannini (eds.), University of Chicago Press.

Froot, K.A. \& J.A. Frankel, Forward discount bias: is it an exchange risk premium?, Quarterly Journal of Economics 104 (1989): 139-161 
Froot, K.A. \& J.A. Frankel, Exchange rate forecasting techniques, survey data, and implications for the foreign exchange market, IMF Working Paper 90/43

International Monetary Fund, Washington, D.C., U.S.A. (1990)

Froot, K.A. \& T. Ramadorai, Currency returns, institutional investor flows and exchange rate fundamentals, mimeo, Harvard University (2002)

Froot, K.A. \& Thaler, R.H., Anomalies: Foreign Exchange, Journal of Economic Perspectives, Vol. 4, No. 3 (1990): 179-192

Glaser, M., T. Langer \& M. Weber, On the trend recognition ability of professional traders: are they better or just more overconfident than lay people?, mimeo, Universität Mannheim (2003).

Goodwin, R.M., Dynamical coupling with especial reference to markets having production lags, Econometrica 15 (1947): 181-204

Griffin, D. \& A. Tversky, The weighing of evidence and the determinants of confidence, Cognitive Psychology 24 (1992): 411-435

Hey, J.D., Expectations formation: rational or adaptive or...? Journal of Economic Behavior \& Organization 25 (1994): 329-349

Hodrick, R.J., The empirical evidence on the efficiency of forward and futures foreign exchange markets, Harwood, London, U.K. (1987)

Hong, H. \& J.C. Stein, A unified theory of underreaction, momentum trading, and overreaction in asset markets, Journal of Finance 54 (1999): 2143-2184

Ito, T., Foreign exchange rate expectations: micro survey data , American Economic Review 90 (1990): 434-449

Jeanne, O. \& A.K. Rose, Noise trading and exchange rate regimes, Quarterly Journal of Economics 117 (2002): 537-569

Kahneman, D. \& A. Tversky, On the psychology of prediction, Psychological Review 80 (1973): 237-251

Keynes, J.M., The general theory of employment, interest and money, Macmillan, London, U.K. (1936)

Lyons, R.K., A simultaneous trade model of the foreign exchange hot potato, Journal of International Economics 42 (1997): 275-298

MacDonald, M. \& I.W. Marsh, Currency forecasters are heterogeneous: confirmation and consequences, Journal of International Money and Finance 15 (1996): 665-685 
MacDonald, R. \& Torrance, T.S., Some survey based tests of uncovered interest parity. In: MacDonald, R. \& Taylor, M.P. (eds.), Exchange rates and open economy macroeconomics (1989), Oxford: Blackwell

Marey, P.S., Exchange rate expectations: controlled experiments with artificial traders, Journal of International Money and Finance 23 (2004): 283-304.

McCallum, B., A reconsideration of the uncovered interest parity relationship, Journal of Monetary Economics 33 (1994): 105-132

Meredith, G. \& Ma, Y., The forward premium puzzle revisited, IMF Working Paper $\mathrm{WP} / 02 / 28(2002)$.

Metzler, L., The nature and stability of inventory cycles, Review of Economic Statistics 29 (1941): 113-129

Muth, J.F., Rational expectations and the theory of price movements, Econometrica 29 (1961): 315-335

Nerlove, M., Adaptive expectations and cobweb phenomena, Quarterly Journal of Economics 72 (1958): 227-240

Newbery, D.M., On the accuracy of the mean-variance approximation for futures markets, Economics Letters 28 (1988): 63-68

Perron, P., Trends and random walks in macroeconomic time series: further evidence from a new approach, Journal of Economic Dynamics and Control 12 (1988): 297-332

Rabin, M., Inference by believers in the law of small numbers, Quarterly Journal of Economics (2002): 775-816

Redman, D., A reader's guide to rational expectations: a survey and comprehensive annotated bibliography, Edward Elgar, Aldershot, U.K. (1992)

Rose, A., Is the real interest rate stable? Journal of Finance 43 (1988): 1095-1112

Sarno, L. \& M.P. Taylor, The economics of exchange rates, Cambridge University Press, Cambridge, U.K. (2002)

Schmalensee, R., An experimental study of expectation formation, Econometrica 44 (1976): $17-41$

Smith, V.L., G.L. Suchanek \& A.W. Williams, Bubbles, crashes, and endogenous expectations in experimental spot asset markets, Econometrica 56 (1988): 1119-1151

Stock, J.H. \& M.W. Watson, Testing for common trends, Journal of the Americal Statistical Association 83 (1988): 1097-1107 
Taylor, M.P., Expectations, risk and uncertainty in the foreign exchange market: some results based on survey data, The Manchester School of Economic and Social Studies 57 (1989): $142-153$

Taylor, M.P. \& H. Allen, The use of technical analysis in the foreign exchange market, Journal of International Money and Finance 11 (1992): 304314

Tversky, A. \& D. Kahneman, Belief in the law of small numbers, Psychological Bulletin 76 (1971): $105-110$

Williams, A.W., The formation of price forecasts in experimental markets, Journal of Money, Credit, and Banking 19 (1987): 1-18

Wu, Y. \& H. Zhang, Mean reversion in interest rates: new evidence from a panel of OECD countries, Journal of Money, Credit \& Banking 28 (4): $604-621$

Zietz, J., Some evidence on the efficiency of the forward market for foreign exchange from Monte-Carlo experiments, The Economic Journal 105 (1995): 1471-1487 